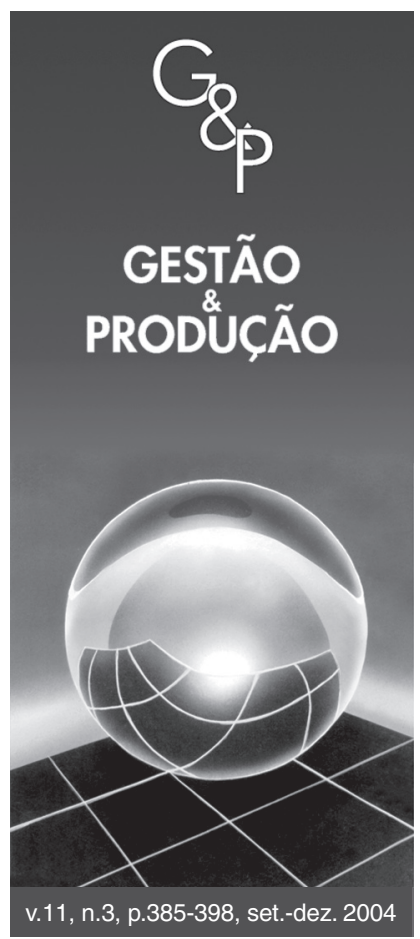

\title{
UM ESTUDO DA COMPETITIVIDADE DOS DIFERENTES CANAIS DE DISTRIBUIÇÃO DE HORTALIÇAS
}

\author{
Ana Elisa Bressan Smith Lourenzani \\ Andrea Lago da Silva \\ GEPAI - Grupo de Estudos e Pesquisas Agroindustriais, \\ Departamento de Engenharia de Produção, \\ Universidade Federal de São Carlos, UFSCar, \\ Rodovia Washington Luís, Km 235, C.P. 676, CEP 13560-970, São Carlos, SP, \\ e-mail: anabressan@yahoo.com, deialago@ power.ufscar.br
}

Resumo

Recebido em 02/7/2004

Aceito em 10/11/2004

As cadeias de suprimentos de hortaliças enfrentam, nos dias atuais, o desafio de alinhar a demanda e a oferta de produtos de maneira eficiente. Do lado da demanda, clientes exigentes, interessados em produtos com qualidade e sempre disponíveis nos pontos de venda. Do lado da oferta, a dificuldade em garantir o produto certo, na hora certa e no local adequado. Percebendo a dificuldade em ligar demanda e oferta, por problemas relacionados, principalmente, à logística e à qualidade, as grandes redes de auto-serviço têm abandonado o sistema tradicional de suprimento de produtos hortícolas, por meio das Centrais Estaduais de Abastecimento Sociedade Anônima (CEASA), e criado centrais próprias de compras onde a aquisição dos produtos é feita diretamente de produtores rurais e atacadistas especializados. No entanto, este novo canal deve ser examinado com cuidado já que, sob certas circunstâncias, pode representar ameaças e oportunidades para o produtor rural. Assim, propõe-se uma análise da competitividade dos principais canais de distribuição de hortaliças, em especial, do tomate in natura, sob a ótica da gestão da cadeia de suprimentos. De forma a alcançar esse objetivo, foi utilizado um método que consiste em estabelecer direcionadores de competitividade para todos os elos da cadeia. Conhecendo as vantagens e limitações de cada canal de distribuição, é possível estudar formas de torná-los mais eficientes. Os resultados, obtidos por meio de pesquisa de campo com os agentes dos canais, demonstram que as cadeias de suprimentos, que optam pela distribuição por meio das centrais de compras de grandes redes de auto-serviço, apresentam melhor desempenho competitivo do que a distribuição por meio das CEASAs. No entanto, o desempenho superior não se mostra sustentável à medida que o diferencial de poder entre os varejistas e os produtores rurais aumenta a rivalidade vertical e permite comportamentos conflitantes $e$ oportunistas.

Palavras-chave: hortaliças, canais de distribuição, gestão da cadeia de suprimentos, competitividade.

\section{Introdução}

A baixa eficiência na distribuição de hortaliças é considerada um dos maiores entraves para o bom desempenho competitivo de toda a cadeia. A alta perecibilidade, que é uma característica inerente a esses produtos, exige um arranjo de canal de distribuição que permita sua comercialização eficiente, o que está, muitas vezes, fora do alcance dos produtores.

Desde a década de 60, a maior parte da comerciali- zação de hortaliças no Brasil tem ocorrido por meio das Centrais Estaduais de Abastecimento Sociedade Anônima (CEASA). Embora o maior volume de comercialização de hortaliças ainda seja feito por meio das CEASAs, os grandes varejistas de auto-serviço têm criado formas alternativas e mais efetivas para adquirir seus produtos. Eles têm desenvolvido centrais próprias, onde a compra de hortaliças in natura é feita, em geral, diretamente dos produtores ou atacadistas especializados. 
Observa-se que as mudanças na estrutura de comercialização têm impactos negativos para a cadeia de hortaliças. À medida que exclui produtores incapazes de atender às exigências das centrais de compras de grandes redes varejistas, traz à tona a ineficiência da comercialização por meio das CEASAs. Considerando os pontos de venda ao consumidor final, as mudanças na estrutura de comercialização tornaram mais difícil a sobrevivência de pequenos varejistas em um mercado no qual poucas grandes redes dominam as fontes mais eficientes de suprimentos em termos de qualidade, logística e demais ferramentas gerenciais.

Nesse contexto, esse artigo teve como objetivo analisar a competitividade dos principais canais de distribuição de tomate in natura no Estado de São Paulo, a partir da análise de direcionadores de competitividade. A partir dessa análise, foi possível conhecer as vantagens e limitações de cada um dos arranjos do canal de distribuição e propor ações que os tornassem mais competitivos. Os resultados obtidos da análise dos canais de distribuição do tomate in natura poderão, em parte, caracterizar problemas associados a outras hortaliças, já que o atacado e o varejo utilizam padrão semelhante para comercializar diversas hortaliças.

\section{Referencial teórico}

\subsection{Gestão da cadeia de suprimentos}

Van Der Vorst et al. (1998) relataram que, tradicionalmente, as informações a respeito da demanda, compartilhadas entre as organizações ao longo de uma cadeia produtiva, restringem-se a pedidos de compras. Considerando que cada organização tende a gerenciar seus dados internos (como padrões de vendas, níveis de estoque, capacidade de produção, etc.) de forma individual, sem compartilhamento de informações entre os agentes, alterações inesperadas nos pedidos de compra irão causar um desequilíbrio à cadeia. Mecanismos para reduzir as incertezas e a complexidade dos processos de decisão podem ser instituídos dentro das organizações. No entanto, os maiores benefícios podem ser alcançados quando esses mecanismos são instituídos de forma interorganizacional, ou seja, quando há certa interação entre as organizações relacionadas, visando a coordenação dos agentes envolvidos nessa cadeia (ou rede) de suprimentos. A coordenação dos sistemas agroalimentares é definida como o resultado da ação de diferentes mecanismos que permitem suprir as necessidades dos consumidores finais (Zylbersztajn, 1995). Essa definição engloba a coordenação por meio de mecanismos de preços, mecanismos contratuais e aspectos institucionais. A coordenação pode também ser definida como a habilidade de transmitir informações, estímulos e controles ao longo das etapas seqüenciais que integram os conjuntos de atividades necessárias para atender ao mercado (Farina e Zylbersztajn, 1994).

Batalha e Silva (1999) consideram que é necessária uma relação direta com a coordenação das atividades de suprimento, produção e distribuição, desenvolvidas pelas empresas de uma cadeia. A gestão desse processo é conhecida como Supply Chain Management (SCM) ou Gestão da Cadeia de Suprimentos. A Gestão da Cadeia de Suprimentos pode ser definida, neste trabalho, como a gestão de uma rede de múltiplos negócios e relacionamentos. É justamente nessa integração e na gestão intra e interorganizacional que surgem um efeito sinérgico e conseqüiente aumento da competitividade da cadeia como um todo.

Hutt e Speh (2001) acrescentaram que as cadeias de suprimentos devem ser gerenciadas de forma integrada, considerando os relacionamentos, a informação e os fluxos de materiais, além dos limites da firma, com o objetivo de diminuir custos e tornar os fluxos mais eficientes. Para esses autores, a gestão da cadeia de suprimentos é vista como um instrumento capaz de construir vantagem competitiva para a cadeia como um todo. Para que esse processo conduza ao aumento da competitividade, é necessário que haja integração, cooperação e compartilhamento de informações, tanto dentro da organização como entre as organizações. Esses autores consideraram ainda que, para incrementar a competitividade, a gestão da cadeia de suprimentos tem como objetivos principais a redução do gasto (desperdício), a redução da defasagem de tempo entre o pedido e a entrega do produto (lead-time), a flexibilidade e a redução do custo unitário.

Omta et al. (2001) destacam que por causa de um ambiente cada vez mais competitivo, no qual a competição não envolve apenas questões relativas a preço, mas também atributos de produto e serviço, a capacidade de construir e manter uma rede de relacionamentos interorganizacionais é vista como um fator chave para alcançar vantagem competitiva sustentável. Neste contexto, Lazzarini et al. (2001) propõem um conceito que busca integrar as teorias de análise de rede e de cadeia de suprimentos, o netchain. Eles relataram que as interdependências verticais, no âmbito da análise das cadeias de suprimentos, requerem um entendimento sistêmico da alocação dos recursos e dos fluxos de informação entre as firmas envolvidas num processo seqüencial de produção. Já, na análise de rede, utilizam-se instrumentos para mapear a estrutura das relações interorganizacionais, tendo como enfoque as relações horizontais entre firmas pertencentes a um grupo em particular. Assim, o netchain pode ser entendido como um conjunto de redes que compreende as ligações horizontais entre as firmas dentro de determinado elo e que são arranjadas de forma seqüencial, com base nas ligações verticais entre eles. Destaca-se que a 
interação das teorias acerca da gestão das cadeias de suprimentos e redes na forma de netchains pode contribuir para a análise da competitividade de determinado sistema. Isso é possível, pois as ações das firmas dentro dos elos da cadeia afetam as transações entre os elos e, assim, o desempenho de todo o sistema.

Lambert et al. (1998) afirmam que a gestão da cadeia de suprimentos consiste na integração de processos de negócios desde o consumidor final até os fornecedores primários de produtos, serviços e informações. Dentro dessa abordagem mais ampla, é possível identificar um outro conceito relevante para a competitividade das cadeias de suprimentos, a gestão dos canais de distribuição. Este conceito é discutido a seguir.

\subsection{Canais de distribuição}

Vários autores descrevem os canais de distribuição. Rosembloom (1999) os define como: o caminho seguido por um produto desde sua concepção até o consumidor final; a transferência de posse entre várias firmas; ou, ainda, define o canal de distribuição como sendo uma coalizão de empresas reunidas com o propósito de realização de trocas. Silva (1999) afirma que os canais de distribuição englobam os agentes que são responsáveis por disponibilizar o produto, desde seu ponto de origem até o consumidor final, da melhor maneira possível. De acordo com Stern et al. (1996), os canais de distribuição consistem em organizações interdependentes, envolvidas no processo de tornar um produto ou serviço disponível para uso e consumo. Os canais de distribuição não devem apenas satisfazer a demanda por meio do fornecimento de mercadorias e serviços no lugar, quantidade, qualidade e preços adequados, mas deve também estimular a demanda por meio de atividades promocionais. Estes autores consideram os canais de distribuição como um sistema pela relação de interdependência entre os agentes que o compõem. Ou seja, os componentes do canal mantêm inter-relações de forma interdependente com o objetivo de produzir um resultado específico.

Os membros do canal desempenham várias funçõeschave, que constituem fluxos para frente, para trás e nos dois sentidos. As funções desempenhadas por diferentes membros do canal são chamadas de fluxos, porque consistem num conjunto de atividades que ocorrem numa sequiência dinâmica dentro do canal de distribuição (Stern et al., 1996). Existem vários fluxos dentro dos canais de distribuição. Entre os mais importantes estão: produto; negociação; propriedade; informação; promoção. Os fluxos devem ser desempenhados pelos participantes que conseguirem operar na forma mais competitiva possível, sendo indispensáveis a experiência, a especialização, os contatos e a escala (Neves, 1999). Assim, essa colocação indica uma das razões pelas quais um canal é formado com determinado arranjo. A informação é fator relevante dentro dos canais, cujo compartilhamento consiste num fator-chave para a coordenação dos fluxos dentro dos canais.

Considerando a contribuição de Rosembloom (1999), que define o canal de distribuição como o caminho seguido pelo produto, desde sua concepção até o consumidor final, é possível inferir que os canais de distribuição dos produtos consumidos in natura, como o objeto de estudo desta pesquisa, são delimitados de forma muito semelhante à cadeia produtiva desses produtos, pois os canais de distribuição desses produtos são relativamente curtos. A diferença que se apresenta é que a cadeia de suprimentos engloba também o setor de insumos, enquanto o canal de distribuição ignora esse elo. Assim, de acordo com esse conceito, os níveis, ou intermediários do canal de distribuição de hortaliças, são aqueles que compõem sua cadeia produtiva, excluindo-se o setor de insumos.

\section{Método}

\subsection{A coleta de dados}

O método adotado nessa pesquisa foi extraído de Silva e Batalha (1999) e consiste em estabelecer direcionadores de competitividade para todos os elos da cadeia. Para cada direcionador de competitividade, foram identificados subfatores possíveis de serem mensurados por meio de informações quantitativas e qualitativas.

A semelhança entre os canais de distribuição de produtos in natura e a sua própria cadeia produtiva permite que seja aplicada ao estudo em questão, sobre os canais de distribuição de tomate in natura, um método para estudo de cadeias. Portanto, a visão sistêmica e a coordenação entre os agentes, que contribuem para tornar a cadeia mais competitiva, também se aplicam ao estudo dos canais de distribuição envolvidos na comercialização desse produto.

Nesse método, as informações podem ser coletadas em fontes secundárias e a partir de entrevistas com "agentes-chave" da cadeia estudada. Os dados de fontes secundárias consistem em informações estatísticas e estudos realizados previamente acerca da comercialização de hortaliças em geral e de tomate in natura, mais especificamente. Essas informações permitiram a elaboração de um diagnóstico preliminar da comercialização de tomate in natura no Estado de São Paulo, a identificação dos agentes-chave da cadeia e o delineamento dos principais canais de distribuição de tomate in natura, além do direcionamento para etapas subseqüentes. No estudo em questão, a escassez de dados confiáveis e a existência de dados conflitantes foram as principais barreiras ao uso de dados secundários, levando à necessidade de realização de entrevistas. 
As entrevistas com os agentes-chave da cadeia foram feitas pessoalmente, utilizando-se questionários semi-estruturados, com os principais agentes econômicos e sociais necessários para o entendimento da dinâmica competitiva da cadeia. Os agentes foram: produtores rurais, intermediários (compradores), atacadistas da CEAGESP e de empresas independentes, varejistas (supermercados, hipermercados, lojas especializadas e sacolões), associações de classe e comercial, órgãos do governo e outros indivíduos que atuam na comercialização do tomate in natura. Pequenas amostras de indivíduos foram identificadas para entrevistas, que serviram de subsídio para a identificação dos fatores que influenciam o desempenho e a eficiência do sistema, bem como o conhecimento do funcionamento dos diferentes canais de distribuição que compõem a cadeia produtiva. Ao todo foram realizadas entrevistas com 27 diferentes agentes, dentre eles: 3 representantes de atividades de apoio; 8 produtores rurais; 5 atacadistas de diferentes portes; 7 varejistas, sendo três das cinco maiores redes varejistas em operação no Brasil, em 2002, redes de pequenos e médios portes e lojas especializadas; e 4 representantes do ambiente institucional.

A pesquisa de campo foi realizada nos principais pólos de produção e comercialização de tomate no Estado de São Paulo. Para levantamento de dados de produção, foram visitados produtores rurais na região de Mogi-Mirim (tomate tipo salada longa-vida), Itapeva (tomate tipo Santa Cruz) e Itapetininga (tomate tipo caqui e cereja). Essas foram indicadas por Camargo e Camargo Filho (1999) como as principais regiões produtoras de tomate in natura no Estado de São Paulo. Já os dados de comercialização foram obtidos na CEAGESP, na CEASA/ Campinas e com atacadistas e varejistas da amostra. A pesquisa foi realizada no período de setembro de 2002 a janeiro de 2003.

\subsection{Direcionadores de competitividade}

Van Duren et al. (1991), em trabalho a respeito da competitividade da indústria agroalimentar do Canadá, elegeram como indicadores de competitividade as variáveis lucratividade e participação no mercado (market share). Esses indicadores podem ser mensurados de forma objetiva, por meio de sua associação com direcionadores de competitividade. Tais direcionadores envolvem os aspectos tecnologia, insumos produtivos, estrutura de mercado, gestão, relações de mercado e ambiente institucional. Cada direcionador foi posteriormente dividido em subfatores, de acordo com as especificidades do segmento estudado ou do sistema como um todo. Cada subfator foi classificado quanto ao seu grau de controlabilidade, podendo ser: controlável pela firma (estratégia, mix de produtos, tecnologia, custos), controlável pelo governo (impostos, juros e câmbio, educação), quase controlável (preços de insumos, condições de demanda) ou incontro- lável (fatores ambientais).

Para avaliação qualitativa da intensidade do impacto dos subfatores e sua contribuição para o efeito agregado dos direcionadores, estabeleceu-se uma escala ordinal, variando de "muito favorável", quando há significativa contribuição positiva do subfator, a "muito desfavorável", no caso da existência de entraves ou mesmo impedimentos, ao alcance ou sustentação da competitividade. Como valores intermediários, foram estabelecidas as categorias "favorável", "neutro" e "desfavorável". A escala é, então, transformada em valores que variam progressivamente, em intervalos unitários, de - 2 para uma avaliação "muito desfavorável" a + 2 para "muito favorável". Desse modo, os resultados da avaliação podem ser visualizados em representação gráfica, bem como ser combinados quantitativamente, para comparações agregadas.

A combinação quantitativa dos subfatores, o que gera uma avaliação para cada direcionador de competitividade, envolve ainda uma etapa de atribuição de pesos relativos. A motivação para esse procedimento de ponderação é o reconhecimento da existência de graus diferenciados de importância para os diversos subfatores, em termos de sua contribuição para o efeito agregado. Por fim, a avaliação final dos direcionadores é obtida por meio da fórmula:

em que:

$$
X=\sum_{i=1}^{n} Z_{i} W_{i} Y_{i}
$$

$X=$ avaliação final do direcionador;

$Z_{i}=$ avaliação atribuída ao subfator $\mathrm{i}$;

$W_{\mathrm{i}}=$ peso atribuído ao subfator $\mathrm{i}$;

$Y_{i}=$ peso atribuído ao direcionador i; e

$n=$ número de subfatores contidos no direcionador.

Com base na avaliação de cada direcionador, foi possível construir representações gráficas que ilustram o resultado da avaliação.

\section{Resultados e discussão}

A seguir estão descritos os resultados obtidos a partir da análise de dados secundários e da pesquisa de campo. Inicialmente, estão descritos os principais canais de distribuição de hortaliças. Em seguida, os direcionadores de competitividade são discutidos em profundidade. Estes são: insumos, tecnologia, estrutura de mercado, relações de mercado, gestão interna e consumo. Por fim, é apresentada a análise da competitividade de cada canal de distribuição, bem como a análise agregada dos canais.

\subsection{A distribuição de hortaliças}

O elo da distribuição de hortaliças foi o principal responsável pelas principais mudanças que ocorreram na 
cadeia nos últimos anos, influenciando a sua eficiência. A comercialização de hortaliças no Brasil tem ocorrido, tradicionalmente, por meio das CEASAs. Nessas centrais não há interferência do governo na negociação e formação de preços, este é apenas responsável pelo gerenciamento do espaço e das atividades, como num condomínio. Nas últimas décadas, diversos problemas têm sido atribuídos a este sistema de comercialização, como sistema logístico ineficiente, alto índice de perdas, embalagens inadequadas e armazenamento deficiente.

Novos canais de distribuição foram desenhados a partir da necessidade de eficiência no suprimento de hortaliças para o auto-serviço. Estes envolvem atacadistas especializados, capazes de fornecer produtos com regularidade, qualidade e preços competitivos e produtores rurais capazes de atender às necessidades do varejo. Ao invés de depender exclusivamente do mercado ou de onerar os custos via integração vertical, as redes de auto-serviço têm adotado formas híbridas (contratos) para realizar as transações. Uma estratégia adotada foi montar estruturas, centrais de compras e distribuição próprias, para a realização das transações comerciais e operações logísticas. Nesse processo, observou-se um processo de exclusão daqueles fornecedores incapazes de atender às exigências impostas (Reardon e Berdegué, 2002). Estes buscaram canais alternativos para o escoamento dos seus produtos como as CEASAs, o setor de refeições coletivas e a venda direta para outros formatos de varejo como sacolões e varejões (Machado e Silva, 2003).

Outros canais de distribuição de hortaliças menos expressivos incluem vendas por telefone, vendas de porta em porta e o comércio eletrônico. As vendas por telefone se referem, em geral, a produtos com alto valor agregado como os produtos orgânicos, enquanto a venda de porta em porta acontece principalmente em pequenas cidades. Já algumas iniciativas de comércio eletrônico foram observadas entre empresas (Business-to-Business), mas em pequena escala por, principalmente, problemas relacionados com a classificação e padronização dos produtos.

Na Figura 1, estão representados os níveis organizacionais ou elos e seus inter-relacionamentos, que compreendem os principais canais de distribuição de hortaliças. Estes arranjos organizacionais podem ser observados em grande parte das hortaliças no Brasil, exceto o grupo das hortaliças de folha, que segue uma dinâmica diferenciada.

O Canal A se refere à distribuição por meio das centrais de compras mantidas pelas redes de auto-serviço. É composto por produtores rurais (geralmente com alto nível tecnológico), atacadistas especializados (que agregam valor aos produtos), centrais de compras de grandes redes de auto-serviço e suas lojas, que distribuem para o consumidor final.

O Canal B se refere à comercialização por meio das CEASAs. É composto por produtores rurais (de alto e baixo níveis tecnológicos), CEASAs, pequenos e médios varejistas, entre eles estão os sacolões, varejões e lojas especializadas, e seus clientes. Os agentes envolvidos nas transações podem variar conforme a demanda, oferta e especificidade requerida. Esta estrutura foi observada para diversas hortaliças. No entanto, são utilizados outros tipos de estruturas para hortaliças de folhas, por sua alta perecibilidade.

A seguir são apresentados alguns aspectos que contribuíram para as mudanças observadas nos canais de distribuição de hortaliças.

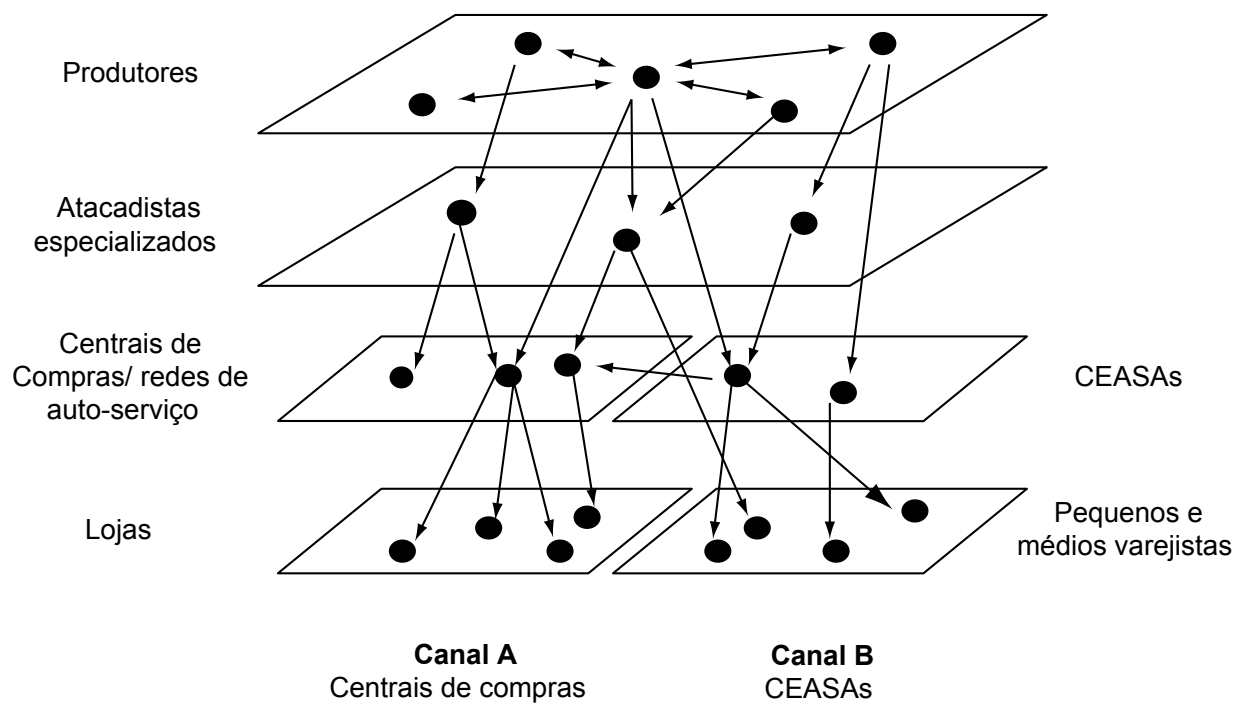

Figura 1. Agentes envolvidos na distribuição de hortaliças (exceto hortaliças de folha) e as relações existentes nos Canais A e B. Fonte: elaborado pelas autoras com base no modelo sugerido por Lazzarini et al. (2001). 


\subsubsection{Insumos}

As embalagens se destacam entre os principais insumos utilizados na distribuição. As embalagens tradicionais destes produtos são as caixas de madeira, que apresentam diversos problemas, como contaminação por pragas e fitopatógenos, pois são reutilizadas diversas vezes; variação no peso e esmagamento e deterioração dos frutos. As altas perdas de hortaliças no varejo podem ser atribuídas, na sua maioria, ao manejo e acondicionamento inadequados. Elas estão também relacionadas com a padronização e classificação deficiente dos produtos. Hoje se tem buscado alternativas para as caixas de madeira. Destacam-se as embalagens de papelão não retornáveis e que permitem a impressão de logotipos e rótulos. As embalagens plásticas são também indicadas por serem reutilizáveis, resistentes, permitirem higienização, além de serem passíveis de formarem pallets.

\subsubsection{Tecnologia}

Considerando a tecnologia adotada na distribuição de hortaliças, destacam-se a Tecnologia de Informação (TI) e a tecnologia de processamento e conservação.

A TI atua como agente dinamizador das mudanças que ocorrem na forma de competir das empresas, orientandoas no sentido de responder de forma eficiente às mudanças que ocorrem no mercado, por meio de um melhor controle e integração dos agentes da cadeia. Algumas redes de auto-serviço alimentar desenvolveram programas que são compartilhados com alguns de seus fornecedores de hortaliças para que os pedidos, notas fiscais, informações logísticas entre outras informações, sejam realizados on line. No entanto, considerando que as grandes redes de auto-serviço montaram centrais de distribuição próprias com o intuito de evitar problemas relacionados com as CEASAs e adquirir produtos diretamente do produtor rural, a tecnologia de informação ainda consiste numa importante barreira. Observa-se que poucos são os fornecedores capazes de adotar estes sistemas, pois, em geral, o nível tecnológico e, principalmente, gerencial, é baixo entre os produtores rurais. Uma maior capacidade gerencial e tecnológica foi observada em atacadistas especializados, nos quais é mais comum a utilização de sistemas de troca de informação.

Visando aumentar a vida pós-colheita das hortaliças, várias tecnologias têm sido adotadas: as embalagens com atmosfera modificada ou controlada, que interferem na concentração de determinados gases que aceleram a maturação dos frutos; e a conservação pelo frio, que desacelera o metabolismo dos frutos, retardando o amadurecimento.

\subsubsection{Estrutura de mercado}

A distribuição de hortaliças é realizada por meio de dois níveis principais: o atacado, representado pelos en- trepostos normatizados (CEASAs) e por firmas independentes; e o varejo, representado por diferentes formatos.

$\mathrm{Na}$ distribuição de hortaliças existem dois tipos claros de atacadistas. O primeiro tipo é representado pelos atacadistas permissionários das CEASAs. Estes realizam, na grande maioria das vezes, transações do tipo spot, marcadas por um comportamento conflitante em relação aos outros elos da cadeia. Além disso, estão sujeitos a incertezas e ao oportunismo do mercado. O segundo tipo é representado pelos atacadistas, localizados dentro ou fora das CEASAs, que buscam agregar valor e serviços à sua competência essencial. Estes promovem o desdobramento das cargas de produtos, selecionando-os, acondicionando-os em embalagens de diversos tamanhos e tipos, e realizando operações logísticas. Dentro deste tipo de atacadistas estão os especializados, localizados próximo às zonas produtoras.

Considerando a alta perecibilidade das hortaliças, os atacadistas, tanto os permissionários das CEASAs quanto os especializados, desempenham papel importante na distribuição. Estes são capazes de fornecer pequenas quantidades de produtos e um mix diversificado, atendendo, assim, a pequenos e médios varejistas.

O setor supermercadista é considerado como um importante canal de distribuição de hortaliças, sendo responsável por cerca de $50 \%$ das hortaliças consumidas no Brasil. Na cidade de São Paulo este valor é de cerca de $30 \%$ por características inerentes aos grandes centros como distâncias até os supermercados, valorização das lojas de vizinhança e existência de feiras-livres nos bairros (Reardon e Berdegué, 2002). Apesar da concentração do mercado, as lojas de pequeno e médio porte são de grande importância para o setor varejista. Em 2001, foram responsáveis por $56 \%$ do abastecimento de alimentos (Costa e Ortiz, 2001). Porém, uma mudança na postura destas lojas é necessária para garantir sua sobrevivência. Os varejões ou sacolões são formatos de varejo também relevantes. A participação deste agente era de 0,8\% em 1983, passando a 15,7\% em 1993 e a 34\% em 2002 (Costa e Ortiz, 2001; Saabor e Rojo, 2002). Isto demonstra que aspectos como conveniência e localização das lojas, além da qualidade dos produtos, que são características deste formato de varejo, estão crescendo na preferência do consumidor.

\subsubsection{Relações de mercado}

$\mathrm{Na}$ distribuição de hortaliças, foram identificados vários tipos de transações dependendo dos agentes envolvidos. As compras no mercado spot, buscando menores custos, consistem numa transação em que o oportunismo e o risco moral (moral harzard) são altos, além disso, existe o risco da falta do produto no momento em que é demandado. O oportunismo se refere à ávida busca de interesses próprios pelos indivíduos, que podem agir de forma não-ética para alcançá-los (Williamson, 1996). Já 
o risco moral surge quando existe assimetria informacional e interesses divergentes entre as partes que realizam as transações. Com base nas entrevistas, foi observado que este tipo de transação ocorre entre supermercados e permissionários das CEASAs e é complementar aos outros tipos, ocorrendo em situações de falta de produto, preços altos, baixa qualidade ou frustrações de safras.

A verticalização foi observada em poucos casos. Este é um tipo de transação muito difícil de ser feito pela diversidade e quantidade de produtos vendidos. Trata-se de uma estrutura de governança do tipo "hierarquia", que é indicada quando a incerteza e a especificidade dos ativos são muito altas. A incerteza corresponde ao desconhecimento sobre a previsão de eventos futuros, enquanto os ativos específicos são aqueles cujo retorno associado a eles depende da continuidade de uma transação específica. Na prática, foi observada integração vertical por parte de pequenos e médios varejistas em situações nas quais existiam problemas de qualidade (frescor), principalmente no caso de hortaliças de folhas, e em situações que a rastreabilidade foi utilizada como estratégia de marketing.

É comum a utilização de estruturas híbridas. Neste tipo de transação, são utilizados contratos formais ou informais que especificam as características da transação. Desta forma, os fornecedores garantem o escoamento da produção, enquanto os compradores garantem o fornecimento dos produtos, atendendo às especificidades exigidas. No entanto, frequientemente, os contratos observados entre fornecedores e centrais de compras das grandes redes de auto-serviço beneficiam as duas partes de forma bastante desigual, pelo poder de barganha exercido pelas redes.

Apesar das mudanças no processo de aquisição de hortaliças por parte das grandes redes, a CEAGESP continua a ser uma importante fonte para formação de preços e suprimento de alguns segmentos do varejo, principalmente pequenos varejistas, mas também para completar, esporadicamente, o mix de produtos demandados pelas grandes redes.

No caso das transações efetuadas entre os permissionários e seus fornecedores, são observadas duas formas distintas. A primeira delas é a compra especulativa, em que o produto é entregue ao permissionário, ainda na lavoura ou nas CEASAs, sem preço previamente determinado (nota fiscal em branco). Este é o tipo mais comum de transação. Apesar de os produtores se mostrarem insatisfeitos com a incerteza relacionada ao preço de venda, estes temem buscar novos clientes, pois a inadimplência neste segmento é muito alta. A outra forma são os contratos informais. Nestes casos, produtores descapitalizados têm suas lavouras financiadas por atacadistas por meio de contratos informais. São os atacadistas quem realizam os cálculos de custo de produção e repassam a diferença para os produtores. $\mathrm{O}$ pagamento dos fornecedores é feito somente no fim da safra. Neste tipo de transação, o comportamento oportunista é comumente observado. Os produtores se sujeitam a esta situação por dois motivos: dificuldade de acesso ao crédito para financiar lavouras; e certeza de pagamento, já que a inadimplência é uma das principais preocupações dos produtores.

$\mathrm{Na}$ distribuição de hortaliças existe grande rivalidade horizontal no varejo pela concentração de mercado. As lojas competem de forma agressiva em relação a preços e serviços, realizando promoções e oferecendo produtos de qualidade superior.

Percebe-se que existe um desequilíbrio em relação ao poder de barganha exercido pelas grandes redes de autoserviço, que detêm grande parcela do mercado varejista, sobre seus fornecedores, revelando uma grande rivalidade vertical. Nas transações realizadas entre produtores rurais e redes de auto-serviço observa-se que, se por um lado as redes garantem a compra de determinados produtos de um fornecedor, por outro lado não permitem que este desenvolva marca própria, tornando mais fácil o processo de alteração de fornecedores.

Iniciativas de coordenação da cadeia têm sido observadas por parte dos grandes varejistas. Estas iniciativas são feitas por meio das exigências a respeito da origem dos produtos (rastreabilidade) e das exigências em qualidade. Isto faz com que os elos a montante trabalhem de forma mais coordenada para atender às necessidades do varejo. Algumas iniciativas também têm sido observadas por parte das associações que congregam produtores de hortaliças orgânicas. Estas associações representam importante papel no planejamento da produção e na comercialização.

Vale destacar que nem sempre as iniciativas de coordenação buscam ganhos compartilhados ao longo da cadeia. A imposição de preço, variação de quantidades e regularidade na aquisição de produtos por parte do varejo levam os produtores a uma situação de incerteza e insegurança, para o planejamento da produção e comercialização.

\subsubsection{Gestão Interna}

Este item se refere à forma como as empresas envolvidas na distribuição são gerenciadas internamente, evidenciando aspectos como recursos humanos, gestão de suprimentos e estoques, gestão da qualidade, marketing, controle financeiro e serviços.

Quanto aos recursos humanos, observa-se que o nível de profissionalização dos diferentes agentes da distribuição de hortaliças é bastante distinto. No atacado, especialmente nos entrepostos atacadistas (CEASAs), a mão-de-obra é pouco qualificada. No varejo também se observam altos níveis de perdas decorrente da exposição, manuseio e condições de estocagem incorretos. Nas grandes redes de auto-serviço, observa-se que há profis- 
sionais capacitados para lidar com perecíveis. Portanto, observam-se as menores taxas de perdas em lojas maiores, $4 \%$, enquanto lojas menores apresentam perdas de cerca de 9\% (Saabor, 1999).

Quanto à gestão de suprimentos, as grandes redes de supermercados identificaram no setor de hortaliças uma forma de incrementar o tráfego interno de clientes e aumentar a freqüência de visitas às lojas. Dados da pesquisa de mercado, realizada pelo Ministério da Integração Nacional, no setor supermercadista do Estado de São Paulo, indicam que a participação de FLV (frutas, verduras e legumes) no faturamento dos supermercados varia em função do porte da loja. Quanto maior a loja, maior é a rentabilidade do segmento. Isto é explicado pelo poder de barganha exercido pelas grandes redes de auto-serviço. Pelo fato de as compras serem centralizadas, as redes adquirem os produtos a preços mais baixos, além de exigirem qualidade superior.

Para estas redes, a falta de regularidade do fornecimento destes produtos na quantidade, padrão de qualidade e variedade desejadas levaram à construção de estruturas próprias para compras e recebimento de mercadorias. Com a implantação destas estruturas, buscou-se evitar problemas relacionados à ineficiência do sistema tradicional de comercialização (CEASAs). Além disso, a gestão de estoques é feita de forma sistematizada, buscando-se estoques mínimos, mas suficientes para suprir as lojas, e exigindo reposição contínua por parte dos fornecedores. As entregas são diárias, sendo que cada fornecedor tem um horário específico para descarregar os produtos. No entanto, as CEASAs ainda representam um importante papel na formação de preços e como regulador da demanda.

As empresas que utilizam este tipo de estrutura consideram como principais vantagens a redução no custo de aquisição, em relação ao atacado convencional, a possibilidade de exercer controle total sobre a qualidade dos produtos (especificidade do produto) e a eliminação dos intermediários. Por outro lado, os custos logísticos envolvidos são muito altos já que todas as entregas são feitas nas centrais, onde os lotes são subdivididos, novos lotes são formados com um mix de produtos e em seguida distribuídos para as lojas. Exceção é feita para folhosas, que são entregues de loja em loja.

No caso dos atacadistas, a gestão de suprimentos é feita de forma diferenciada entre os atacadistas especializados e os permissionários das CEASAs. Percebe-se que estas ferramentas gerenciais são utilizadas de forma mais intensiva e eficiente nos atacadistas especializados, que buscam trabalhar com estoques mínimos. No caso dos permissionários das CEASAs, foi observado que na gestão de suprimentos e estoques não existe um procedimento sistematizado. Considerando a gestão de estoques, os permissionários realizam as compras intuitivamente, sen- do que a previsão de demanda é baseada na experiência.

A qualidade é considerada um problema na distribuição de hortaliças. As elevadas perdas no varejo não provêm apenas da manipulação do consumidor, mas refletem problemas de tombamento, contaminação, acondicionamento e armazenamento inadequados no campo e nos atacadistas. Acredita-se que a baixa qualidade esteja relacionada à pouca capacitação da mão-de-obra e à infra-estrutura deficiente de alguns estabelecimentos.

A utilização de padrões privados próprios, para as hortaliças e frutas, estabelecidos pelas principais redes varejistas consistem numa tentativa de informar o fornecedor da qualidade exigida, para atender às exigências do consumidor. Estes padrões determinam desde o ponto de colheita até os tipos de embalagens em que os produtos serão entregues. A exigência de padrões privados consiste numa forma de coordenar a cadeia, sendo que as grandes redes são os agentes coordenadores. No caso das CEASAs, existem padrões públicos para os produtos. No entanto, são considerados ineficientes para alguns produtos como, por exemplo, o tomate in natura que tem seus padrões baseados em tamanho dos frutos, desconsiderando o grau de maturação e a integridade dos frutos. Desta forma a mensuração da qualidade torna-se muito difícil, favorecendo ações oportunistas.

As alterações no perfil do consumidor têm provocado mudanças em aspectos de marketing em toda a cadeia produtiva. Na produção, observa-se a criação de marcas próprias para os seus produtos, utilizando embalagens diferenciadas que levam informações até o consumidor final. Iniciativas semelhantes são observadas no atacado. Porém, as iniciativas de criação de marcas encontram uma grande barreira no varejo, principalmente nos grandes varejistas. Estes não permitem o fortalecimento das marcas, para que o fornecedor não tenha poder de barganha no momento da negociação.

É no setor varejista que as estratégias de marketing são mais aplicadas. Percebe-se a utilização das quatro variáveis do composto mercadológico, produto, preço, promoção e ponto de venda. Assim, algumas destas variáveis resultaram em mudanças no layout das lojas, com o aumento da área reservada a hortaliças e transferência para o centro ou entrada da loja, posicionando-as como um chamariz para os clientes. A criação de dias de promoção, com preços baixos para este setor, é vista como forma de atrair os consumidores.

A gestão de custos é considerada essencial para o gerenciamento eficiente das empresas. Na distribuição, os estabelecimentos de menor porte são, em geral, os mais deficientes quanto ao controle de custos. Nos atacadistas de maior porte, é comum o uso de contabilidade. Nas grandes redes varejistas, observou-se um controle rigoroso dos custos e receitas com a utilização de sistemas próprios.

O mix de serviços é uma ferramenta-chave para que as 
lojas se diferenciem umas das outras. No varejo estes serviços incluem a aceitação de pedidos por telefone, correio ou Internet, a entrega em domicílio, a propaganda, os horários de funcionamento, trocas e devoluções, etc. Para o atacado especializado, os serviços estão relacionados principalmente com o sortimento de produtos e embalagens, fornecimento de crédito e entregas. Isto consiste numa vantagem frente aos atacadistas localizados nas CEASAs que oferecem, em geral, menos serviços. Lojas especializadas e sacolões são os formatos de varejo que oferecem os maiores níveis de serviço como informação ao cliente, entregas e crédito, entre outros.

\subsubsection{Consumo}

Fatores demográficos, como o aumento da participação da mulher no mercado de trabalho e a valorização das dietas saudáveis, levaram a mudanças nos padrões de consumo de hortaliças. Nos últimos anos, diferentes formas de agregação de valor podem ser identificadas. Entre elas, destacam-se: os vegetais congelados, os minimamente processados, o uso de embalagens atrativas, capazes de manter a qualidade e integridade do fruto, e a exploração de nichos de mercado para produtos não-convencionais. Outra forte tendência é o cultivo orgânico, ou seja, sem agrotóxicos ou fertilizantes químicos.

Uma pesquisa de mercado de hortifrutícolas aplicada ao setor supermercadista do Estado de São Paulo, realizada pelo Ministério da Integração Nacional (Saabor, 1999), apresenta o perfil do consumidor de hortaliças. Essa pesquisa indica que a renda média familiar desse consumidor é de 11,5 salários mínimos, variando um pouco, com relação ao interior do estado e à capital, o que demonstra que, para a população de baixa renda, o consumo de hortifrutícolas não é considerado essencial. De acordo com a pesquisa, $75 \%$ dos consumidores são mulheres e $90 \%$ têm o primeiro ou o segundo grau de escolaridade. Esses consumidores preferem comprar hortaliças e frutas vendidas a granel, ao invés de produtos embalados, pois a facilidade de perceber atributos de qualidade é maior. Nesse caso, é possível selecionar os melhores frutos, considerando que a qualidade é medida em termos de cor, formato, firmeza e integridade do produto. Já os produtos embalados têm, como atributos positivos, a higiene e a conveniência, além da economia nos custos de mensuração, o que está diretamente relacionado com a transação.

Saabor (1999) reportou que, em 1999, o formato de varejo preferido para a compra de hortifrutícolas era o supermercado, em razão, principalmente, da higiene, da praticidade e do atendimento. Nesse ano, a porcentagem correspondente às compras realizadas nos supermercados era de 47\%. Já, em pesquisa realizada em 2002 (Saabor e Rojo, 2002), foi verificado que os supermercados são os locais preferidos de compra de hortifrutícolas de
$76 \%$ dos consumidores paulistas. Isso indica a importância crescente deste formato de varejo na distribuição de produtos. Essas informações são importantes para que os diferentes formatos de varejo busquem direcionar suas estratégias de marketing para determinado segmento de mercado. Estas podem também influenciar a gestão da cadeia de suprimentos, considerando a especificidade dos ativos e as formas das transações para os diferentes formatos de varejo.

Finalmente, buscando alavancar o consumo de hortaliças, alguns países têm desenvolvido programas de incentivo ao consumo. Entre os mais conhecidos estão o Five a day - fruits and vegetables for better health (Cinco frutas e vegetais diários para melhorar a saúde) nos Estados Unidos, que incentiva a população a consumir cinco porções diárias de frutas e vegetais. O programa conta com a participação do setor varejista, no sentido de incentivar o consumidor final, e oferece também treinamento específico para o setor de refeições coletivas. No Brasil ainda não foram observadas iniciativas semelhantes. Ações assim poderiam, além de incentivar o consumo, tornar o mercado de hortaliças mais dinâmico, gerando empregos e ajudando a manter o homem no campo.

\subsection{Análise da competitividade dos Ca- nais $A$ (Centrais de compras) e $B$ (CE- ASAs)}

Na Tabela 1, estão listados os subfatores que foram examinados na análise da competitividade dos dois canais de distribuição. A partir dos valores gerados nessa tabela, foi possível a construção de representações gráficas que facilitam a visualização da análise da competitividade dos Canais A e B.

$\mathrm{Na}$ análise global dos direcionadores de competitividade, é possível verificar que os canais apresentam desempenho diferente dos direcionadores de competitividade, como ilustrado na Figura 2.

Canal A - Distribuição por meio das centrais de compras de redes de auto-serviço.

Foram identificados como pontos positivos nesse canal os sistemas de padronização próprios, desenvolvidos pelas redes de auto-serviço. Estes sistemas determinam a qualidade mínima e as embalagens nas quais os produtos devem ser entregues. Desta forma, problemas recorrentes nas CEASAs, por causa das embalagens e condições de armazenamento inadequadas, não são observados neste canal. Além disso, este canal apresenta uma infra-estrutura logística favorável. As iniciativas de rastreabilidade e certificação, no caso de produtos orgânicos, também foram consideradas positivas.

Por outro lado, foram identificados dois principais pontos críticos na distribuição por meio do Canal A: o grau de concentração do varejo e o comportamento conflitante entre os varejistas e seus fornecedores. O elevado 
Tabela 1. Análise dos direcionadores de competitividade dos Canais A e B.

\begin{tabular}{|c|c|c|c|c|c|c|}
\hline \multirow{2}{*}{ Direcionadores e Subfatores } & \multirow{2}{*}{$\begin{array}{c}\text { Peso direcionador } \\
(Y)\end{array}$} & \multicolumn{2}{|c|}{ Avaliação subfator $(Z)$} & \multirow{2}{*}{$\begin{array}{c}\text { Peso subfator } \\
(W)\end{array}$} & \multicolumn{2}{|c|}{ Avaliação final $(X)$} \\
\hline & & Canal A & Canal B & & Canal A & Canal B \\
\hline \multicolumn{7}{|l|}{ TECNOLOGIA } \\
\hline Tec. Informação & \multirow{5}{*}{0,10} & 1 & -1 & 0,20 & 0,020 & $-0,020$ \\
\hline Tec. Processamento & & 1 & -1 & 0,30 & 0,030 & $-0,030$ \\
\hline Tec. Conservação & & 0 & -2 & 0,20 & 0,000 & $-0,040$ \\
\hline Sazonalidade & & -2 & -2 & 0,30 & $-0,060$ & $-0,060$ \\
\hline TOTAL & & & & 1,00 & $-0,010$ & $-0,150$ \\
\hline \multicolumn{7}{|l|}{ INSUMOS } \\
\hline Embalagem e rotulagem & \multirow{4}{*}{0,15} & 1 & -1 & 0,35 & 0,053 & $-0,053$ \\
\hline Infra-estrutura & & 1 & -1 & 0,25 & 0,038 & $-0,038$ \\
\hline Matéria-prima & & 1 & -1 & 0,40 & 0,060 & $-0,060$ \\
\hline TOTAL & & & & 1,00 & 0,150 & $-0,150$ \\
\hline \multicolumn{7}{|l|}{ ESTRUTURA DE MERCADO } \\
\hline Grau de concentração & \multirow{6}{*}{$\mathbf{0 , 2 0}$} & -1 & 0 & 0,40 & $-0,080$ & 0,000 \\
\hline Economia de escala & & 1 & 1 & 0,10 & 0,020 & 0,020 \\
\hline Diferencição de serviços & & 1 & 1 & 0,10 & 0,020 & 0,020 \\
\hline Localização & & 1 & 1 & 0,15 & 0,030 & 0,030 \\
\hline Acesso ao mercado por peq/médios produtores & & -2 & 1 & 0,25 & $-0,100$ & 0,050 \\
\hline TOTAL & & & & 1,00 & $-0,140$ & 0,090 \\
\hline \multicolumn{7}{|l|}{ GESTÃO INTERNA } \\
\hline Recursos humanos & \multirow{8}{*}{$\mathbf{0 , 1 0}$} & 1 & -1 & 0,10 & 0,010 & $-0,010$ \\
\hline Gestão de suprimentos & & 1 & -1 & 0,20 & 0,020 & $-0,020$ \\
\hline Gestão de estoques & & 1 & -1 & 0,15 & 0,015 & $-0,015$ \\
\hline Gestão da qualidade & & -1 & -1 & 0,15 & $-0,015$ & $-0,015$ \\
\hline Marketing & & 1 & -1 & 0,15 & 0,015 & $-0,015$ \\
\hline Controle de custos & & 1 & 1 & 0,10 & 0,010 & 0,010 \\
\hline Serviços & & 1 & 1 & 0,15 & 0,015 & 0,015 \\
\hline TOTAL & & & & 1,00 & $\mathbf{0 , 0 7 0}$ & $-0,050$ \\
\hline \multicolumn{7}{|l|}{ RELAÇÕES DE MERCADO } \\
\hline Parcerias e contratos & \multirow{6}{*}{$\mathbf{0 , 2 0}$} & -1 & -1 & 0,20 & $-0,040$ & $-0,040$ \\
\hline Intermediários & & -2 & 0 & 0,10 & $-0,040$ & 0,000 \\
\hline Rivalidade horizontal & & 1 & 1 & 0,10 & 0,020 & 0,020 \\
\hline Rivalidade vertical & & -1 & -1 & 0,20 & $-0,040$ & $-0,040$ \\
\hline Poder de barganha & & -2 & -1 & 0,40 & $-0,160$ & $-0,080$ \\
\hline TOTAL & & & & 1,00 & $-0,260$ & $-0,140$ \\
\hline \multicolumn{7}{|l|}{ AMBIENTE INSTITUCIONAL } \\
\hline Legislacao sanitária & \multirow{9}{*}{0,15} & 0 & 0 & 0,10 & 0,000 & 0,000 \\
\hline Fiscalizacão & & 0 & 0 & 0,10 & 0,000 & 0,000 \\
\hline Padronização e classificação & & 1 & -1 & 0,25 & 0,038 & $-0,038$ \\
\hline Rastreabilidade & & 1 & -1 & 0,20 & 0,030 & $-0,030$ \\
\hline Certificação & & 1 & 0 & 0,15 & 0,023 & 0,000 \\
\hline Câmbio & & 0 & 0 & 0,05 & 0,000 & 0,000 \\
\hline Tributação & & -1 & -1 & 0,10 & $-0,015$ & $-0,015$ \\
\hline Crédito & & 1 & -1 & 0,05 & 0,008 & $-0,008$ \\
\hline TOTAL & & & & 1,00 & 0,083 & $-0,090$ \\
\hline \multicolumn{7}{|l|}{ CONSUMO } \\
\hline Frescor & & 1 & -1 & 0,20 & 0,020 & $-0,020$ \\
\hline Imagem & & 1 & 1 & 0,15 & 0,015 & 0,015 \\
\hline Conveniência & & 1 & -1 & 0,05 & 0,005 & $-0,005$ \\
\hline Preço & $\mathbf{0 , 1 0}$ & 1 & 1 & 0,20 & 0,020 & 0,020 \\
\hline Disponibilidade inf. ao consumidor & & -1 & -1 & 0,10 & $-0,010$ & $-0,010$ \\
\hline Potencial de mercado & & 2 & 1 & 0,15 & 0,030 & 0,015 \\
\hline Segurança & & -1 & -1 & 0,15 & $-0,015$ & $-0,015$ \\
\hline TOTAL & & & & 1,00 & 0,065 & 0,000 \\
\hline TOTAL GERAL & 1,00 & & & & & \\
\hline
\end{tabular}

grau de concentração do varejo tem permitido a adoção de políticas de aquisição que afetam a rentabilidade dos produtores rurais, o que acaba por afetar as relações de médio e longo prazo de toda a cadeia. $\mathrm{O}$ acesso ao mercado por pequenos e médios produtores é considerado muito desfavorável, à medida que as exigências impostas por este canal são incompatíveis com a capacidade pro- dutiva e gerencial destes produtores. Já o comportamento conflitante entre os varejistas e seus fornecedores deve-se ao diferencial de poder de barganha exercido pelas redes frente a seus fornecedores. Durante a pesquisa de campo observou-se uma rivalidade vertical marcante. A análise das parcerias e contratos revelou que por um lado existem parcerias que beneficiam ambas as partes, por outro 


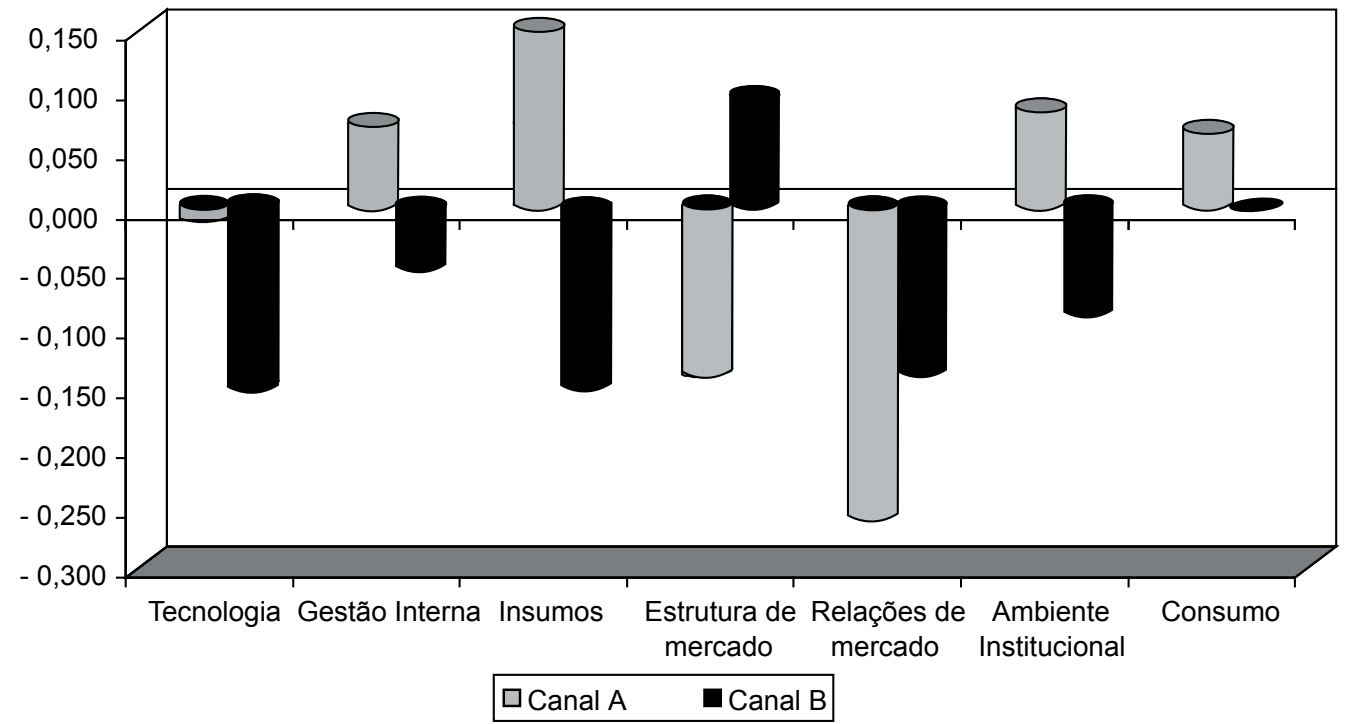

Figura 2. Análise da competitividade dos Canais A e B.

lado a maioria dos contratos beneficia as partes de forma muito desbalanceada. A alternância de aquisição de fornecedores contratados exemplifica este comportamento.

\section{Canal B - Distribuição por meio das Centrais de Abastecimento (CEASAs)}

A partir dos dados coletados, a análise do Canal B indicou que apenas a estrutura de mercado foi considerada um ponto positivo. A principal razão foi o acesso ao mercado por pequenos e médios produtores rurais. A localização também contribuiu positivamente tanto para os varejistas quanto para as CEASAs. Os pequenos e médios varejistas, cujos maiores fornecedores são as CEASAs, apresentam uma distribuição geográfica que permite um acesso muito mais fácil e rápido por parte do consumidor.

Como pontos críticos foram identificados: a baixa qualidade da matéria-prima, a marcante rivalidade vertical entre os agentes e a escassez de utilização de ferramentas de gestão ao longo da cadeia. Os problemas com a qualidade da matéria-prima estão ligados ao baixo nível tecnológico dos agentes envolvidos, aos problemas em relação à padronização e classificação deficientes, à dificuldade de implantação da rastreabilidade pela falta de informação por parte dos produtores rurais e pela falta de incentivos por parte dos outros componentes desse canal. Em relação à rivalidade vertical entre os agentes, observa-se que os contratos informais estabelecidos entre os permissionários e os produtores rurais acontecem em situação de assimetria de informação, podendo gerar comportamentos oportunistas. Esses comportamentos dificultam a implementação de qualquer prática gerencial ao longo da cadeia. Outros aspectos como gestão de estoques, custos e qualidade também precisam ser melhorados. No caso do marketing, observa-se que poucas são as iniciativas de fortalecer a imagem das hortaliças no mercado, ressaltando suas características nutricionais e terapêuticas.

\section{Análise agregada dos Canais A e B}

A tecnologia é um aspecto considerado desfavorável para todos os agentes. A distribuição por meio do Canal A mostra-se menos desfavorável, à medida que este utiliza melhor as tecnologias disponíveis. Este é um aspecto relevante a ser considerado por todo o canal, uma vez que, sob a ótica da gestão da cadeia de suprimentos, se busca pela integração dos processos de negócios e da tecnologia, em especial de informação.

Como discutido anteriormente, os aspectos relacionados à gestão são favoráveis apenas para o Canal A. A produção é o elo que mais necessita implementar ferramentas gerenciais.

Quanto aos insumos, pode-se inferir que a produção é favorável pela disponibilidade dos recursos produtivos. $\mathrm{O}$ Canal A é também favorável, pois exerce maior controle sobre a qualidade e o fornecimento de matéria-prima e tem fácil acesso aos insumos para a comercialização. Já o Canal B mostra-se desfavorável pela falta de controle sobre a matéria-prima e os problemas relacionados às embalagens e à rotulagem. Considerando o processo de gestão da cadeia de suprimentos, o processo de monitoramento e a conferência de produtos comprometem a confiança entre os agentes e a eficiência dos processos de negócios.

Com base no desempenho do direcionador estrutura de mercado, é possível observar que os maiores problemas estão relacionados com o Canal A, por causa, principalmente, da concentração de poder das redes varejistas nesse segmento, levando a um desequilíbrio do poder de barganha de seus fornecedores. A dificuldade de acesso a esse canal por pequenos e médios produtores também contribuiu para esse desempenho negativo. O desequilíbrio em 
termos de poder de barganha pode levar a comportamentos oportunistas e a dificuldade de construir relacionamentos mais colaborativos ao longo do tempo, que é um dos objetivos da gestão da cadeia de suprimentos, conforme discutido por alguns autores, dentre eles, Pires (2004). A análise do Canal B e da produção indicou que esses se encontram numa situação de maior equilíbrio. Isso pode ser explicado, entre outros fatores, pela inexistência de barreiras às transações entre esses dois agentes.

$\mathrm{O}$ ambiente institucional consiste num entrave para a competitividade do Canal B e da produção. As razões, já citadas, estão relacionadas com a padronização e rastreabilidade e a dificuldade de obtenção de crédito, fora a lentidão do sistema judiciário. Esses fatores refletem em dificuldades quanto ao compartilhamento de informações e à confiança entre as organizações que compõem as cadeias de suprimentos, comprometendo a eficiência de todo o processo de gestão.

Considerando o direcionador consumo, percebe-se que este afeta, de forma positiva, a competitividade do Canal A. Aspectos como frescor, preço e conveniência, pela maior oferta de tipos de embalagens, são considerados positivos. No entanto, alguns aspectos como segurança do alimento e informação ao consumidor precisam ser melhorados. A segurança do alimento é um subfator negativo, à medida que o custo de monitoramento da utilização de insumos e qualidade da água na cultura do tomate, entre outros aspectos, é muito elevado. Como este não é um aspecto facilmente percebido pelo consumidor, não há um incentivo imediato para a implantação de programas de certificação de origem. Esses programas contribuiriam para a competitividade do canal em termos de segurança do alimento, rastreabilidade do produto e, portanto, mais informação disponível para o consumidor final.

\section{Considerações finais e implicações gerenciais}

Como contribuições práticas, observa-se que alguns pontos devem ser melhorados, no sentido de melhorar a coordenação e, conseqüentemente, a competitividade das diferentes cadeias de suprimentos. Estas ações, verificadas para o caso de tomate in natura, podem ser utilizadas também para outros produtos, que tenham características semelhantes, como outras hortaliças.

A pesquisa de campo revelou que, quando cada canal é observado individualmente, cada um deles apresenta entraves à competitividade da cadeia como um todo. Por exemplo, o Canal B apresenta uma série de problemas relacionados aos fatores discutidos neste trabalho, mostrando-se menos eficiente. Entretanto, tem um papel fundamental para aqueles produtores excluídos do canal A e para o pequeno varejo, que utiliza este canal para seu abastecimento. Assim, ações visando amenizar os pontos críticos deste canal, como a baixa qualidade da matéria-prima, a rivalidade vertical e a falta de adoção de ferramentas gestão, e aumentar sua competitividade são de grande relevância. Entre estas ações podem ser sugeridas: a implantação de obrigatoriedade de adoção de padrões públicos visando a melhorias na qualidade e segurança do alimento; a difusão da tecnologia de informação, que servirá como base para a implementação de ferramentas de gestão, que possibilitem o incremento gerencial da cadeia e a possibilidade de novos negócios; e a difusão de técnicas de pós-colheita e embalagens adequadas ao acondicionamento de hortaliças entre os produtores e atacadistas das CEASAs, com gradativa proibição das embalagens que causam injúrias aos produtos.

Embora o Canal A apresente melhor desempenho competitivo, essa vantagem não é sustentada em bases fortes pelo resultado negativo do item relações de mercado. A longo prazo, são recomendadas mudanças quanto à gestão de suprimentos, inclusive contratos e parcerias, buscando amenizar a rivalidade vertical e fortalecer relações baseadas em ganhos compartilhados, que tendem a ser sustentáveis. Além disso, o Canal A deve incentivar ações coletivas de pequenos produtores rurais, para permitir o acesso destes ao mais importante canal de distribuição, utilizando esse apelo de marketing para atrair e fidelizar seus clientes.

No entanto, se considerarmos a cadeia de suprimentos sob uma visão sistêmica, é possível concluir que os principais entraves estão relacionados com o direcionador relações de mercado. Os resultados indicam questões de oportunismo e de imposição de regras para aquisição e comercialização de produtos, problemas que afetam toda a cadeia de suprimentos. Isso caracteriza um comportamento adversário, resultado de interesses conflitantes dos diferentes agentes ao longo do canal. Do ponto de vista da eficiência da cadeia como um todo, este comportamento consiste numa importante barreira para iniciativas de colaboração entre os diferentes agentes. Sugere-se a investigação de possíveis práticas não-competitivas seguidas por grandes redes varejistas de forma a amenizar esse problema.

Conclui-se que este trabalho atendeu ao seu objetivo de analisar a competitividade dos principais canais de distribuição de hortaliças no Estado de São Paulo, em especial o caso do tomate in natura, buscando contribuir com proposições para a sua melhoria sistêmica. Como contribuição teórica, verificou-se que o método, inicialmente proposto para análise de competitividade de cadeias produtivas, mostrou-se adequado para a análise da competitividade de canais de distribuição, podendo ser adotado em trabalhos semelhantes.

\section{Agradecimento}

As autoras agradecem o apoio financeiro dado pela Fundação de Amparo à Pesquisa do Estado de São Paulo (FAPESP). 
BATALHA, M.O.; SILVA, A.L. Gestão de cadeias produtivas: novos aportes teóricos e empíricos. In: (Des)Equilíbrio Econômico \& Agronegócio. Viçosa: Editora da UFV, 1999. p. 249-266.

CAMARGO, A. M. M. P.; CAMARGO FILHO, W. Mercado regional de hortaliças e mercosul: ações de governo em economia globalizada. Informações Econômicas, São Paulo, v. 29, n. 12, p. 35-48. 1999.

COSTA, F.; ORTIZ, C. Changes in food consumption patterns in Brazil. Rabobank International. Industry note. Food \& Agribusiness Research. 2001. Disponível em: <http://www.rabobank.com>. Acesso em: 10/03/2002.

FARINA, E. M. M. Q.; ZYLBERSZTAJN, D. Competitividade e organização das cadeias agroindustriais. Costa Rica: Instituto Interamericano de Cooperação para a Agricultura, 1994.

HUTT, M. D.; SPEH, T. W. Business Marketing Management - a strategic view of industrial and organizational markets. 7 ed. USA: Harcourt College Publishers, 2001. 716 p.

LAMBERT, D. M.; COOPER, M. C.; PAGH, J. D. Supply chain management: implementation issues and research opportunities. The International Journal of Logistics Management, v. 9, n. 2, p. 1-19, 1998.

LAZZARINI, S. G.; CHADDAD, F.; COOK, M. L. Integrating supply chain and network analysis: the study of netchains. Journal on Chain and Network Science, v. 1, n. 1, p. 7-22, 2001.

MACHADO, M. D.; SILVA, A. L. Distribuição de Produtos da Agricultura Familiar: uma análise exploratória no varejo. In: Proceedings of IV International Conference on Agri-food chain/networks economics and management. Ribeirão Preto: FEARP/USP, 2003.

NEVES, M. F. Um Modelo para Planejamento de Canais de Distribuição no Setor de Alimentos, 1999. 187 f. Tese (Doutorado em Administração) - Faculdade de Economia, Administração e Contabilidade, Universidade de São Paulo, São Paulo, 1999.

OMTA, S. W. F.; TRIENEKENS, J. H.; BEERS, G. Chain and network science: a research framework. Journal on Chain and Network Science, v. 1, n. 1, p. 1-6, 2001.

PIRES, S. R. I. Gestão da Cadeia de Suprimentos: conceitos, estratégias, práticas e casos. 1 ed. São Paulo:
Atlas, 2004. 310 p.

REARDON, T.; BERDEGUÉ, J. A. The rapid rise of supermarkets in Latin America: challenges and opportunities for development. Development Policy Review, v. 20, n. 4, p. 371-388, 2002.

ROSEMBLOOM, B. Marketing Channels: a management view. Orlando (FL): The Dryden Press, 1999.

SAABOR, A. Uma perspectiva de mercado para a agricultura irrigada. FRUTIFATOS: Informação para a fruticultura irrigada. Ministério da Integração Nacional/Secretaria de Infra-estrutura Hídrica. v. 1, n. 1, set. 1999. Disponível em: <http://www.irrigar.org.br/frutifatos.php>. Acesso em: 26/05/2002.

SAABOR, A.; ROJO, F. O que pensa o consumidor. SuperHiper, São Paulo, p. 158-168, maio, 2002.

SILVA, A. L. A adoção de tecnologia de informação em canais de distribuição. 1999. Tese (Doutorado em Administração) - Faculdade de Economia, Administração e Ciências Contábeis, Universidade de São Paulo, São Paulo, 1999.

SILVA, C. A. B.; BATALHA, M. O. Competitividade em Sistemas Agroindustriais: Metodologia e Estudo de Caso. In: II Workshop Brasileiro Sobre Gestão de Sistemas Agroalimentares. Ribeirão Preto. Ribeirão Preto: FEARP/USP, 1999.

STERN, L. W.; EL-ANSARY A. I. COUGHLAN, A. T. Marketing channels. 5 ed. Englewood Cliffs: Prentice - Hall, 1996.

VAN DER VORST, J. G. A. J; BEULENS A. J. M.; DE WIT, W.; VAN BEEK, P. Supply chain management in food chains: improving performance by reducing uncertainty. Int. Trans. Opl. Research, v. 5, n. 6, p. 478-499, 1998.

VAN DUREN, E.; MARTIN, L.; WESTGREN, R.; Assessing the Competitiveness of Canada's Agrifood Industry. Canadian Journal of Agricultural Economics, n. 39, p.727-738, 1991.

WILLIAMSON, O. E. The mechanisms of governance. 1.ed. New York: Oxford University Press, 1996. 429 p.

ZYLBERSZTAJN, D. Estrutura de governança e coordenação do agribusiness: uma aplicação da nova economia das instituições. 1995. 238f. Tese (Livre Docência) - Faculdade de Economia, Administração e Contabilidade, Universidade de São Paulo, São Paulo, 1995. 


\title{
A STUDY OF THE COMPETITIVENESS OF DIFFERENT FRESH PRODUCE DISTRIBUTION CHANNELS
}

\begin{abstract}
Many retailers have stopped using traditional fresh produce supply channels through government entrepôts because of problems mostly involving poor logistics and quality. To meet retail demand, new supply structures have been developed whereby products are purchased from growers or specialized wholesalers. This supply channel should be closely examined since, under certain circumstances, it may offer both threats and opportunities for producers. We therefore analyzed the efficiency of the main fresh vegetable distribution channels and found that ways to render supply channels more efficient can be identified by pinpointing the channels' advantages and barriers. The findings obtained from a field research indicated that distribution through retail supply structures is more efficient than through government entrepôts However, although retail supply structures show a better performance, this performance does not seem sustainable because the difference in power between retailers and producers leads to conflicting and opportunistic practices.
\end{abstract}

Keywords: fresh produce, marketing channels, supply chain management, competitiveness. 